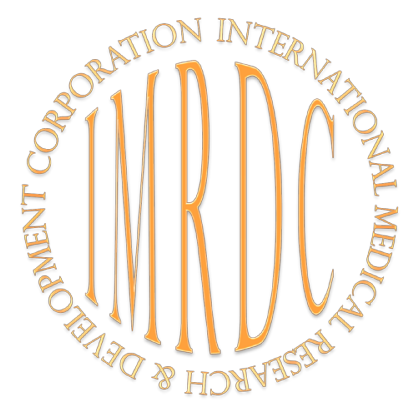

\title{
Effect of Air-Abrasion on Shear Bond Strength of Resin Composite to Dentin: A Study in Vitro
}

\author{
Timur V. Melkumyan ${ }^{1 *}, \mathrm{PhD}, \mathrm{ScD}$; Shahnoza K. Musashaykhova ${ }^{1}$; \\ Fatima Yu. Daurova ${ }^{2}, \mathrm{PhD}$, ScD; Nuriddin Kh. Kamilov'; \\ Surayo Sh. Sheraliyeva ${ }^{1}, \mathrm{PhD}$; Angela D. Dadamova ${ }^{1}$ \\ ${ }^{1}$ Tashkent State Dental Institute, Tashkent, Uzbekistan \\ ${ }^{2}$ Peoples' Friendship University of Russia (RUDN University), Moscow, Russia
}

\begin{abstract}
The purpose of this study was to evaluate in vitro the efficacy of alumina, sodium bicarbonate and erythritol-based tooth air-abrasion on shear bond strength (SBS) of resin composite to dentin.

Methods and Results: In order to assess the strength of the adhesive bond of the resin composite to tooth dentin, 50 tooth samples were prepared in accordance with the Ultradent Shear Bond Test method. All samples were divided into 5 groups. In Group $1(\mathrm{n}=10)$ and Group $2(\mathrm{n}=10)$, for air-abrasion of dentin surface 2 powders based on aluminum oxide with a particle size of $50 \mu \mathrm{m}$ and $27 \mu \mathrm{m}$, respectively, were used (RONDOflex plus 360, KaVo, Biberach, Germany). In Group 3 (n=10) and Group $4(\mathrm{n}=10)$, other abrasive powders based on sodium bicarbonate $(40 \mu \mathrm{m})$ and erythritol $(14 \mu \mathrm{m})$, respectively, were used for a similar purpose (Air-Flow Classic comfort, Air-Flow Plus, EMS, Nyon, Switzerland). The control group $(\mathrm{n}=10)$ consisted of the remaining tooth samples in which the dentin surface, after preparation with a carbide bur, was not subjected to an air-abrasion. The one-day adhesive strength of bonded interfaces was evaluated on an UltraTester device (Ultradent Products Inc., USA) after resin bonding without aging simulation. The speed of movement of the test clamp with the installed sample was set to $1 \mathrm{~mm} / \mathrm{min}$. The maximal value of bonding failure was fixed in pounds (lb). The dentin surface ultrastructure was studied on 10 additional tooth samples, which were prepared for SEM analysis.

It was found that the treatment of dentin surface with air-abrasive powders based on alumina $(50 \mu \mathrm{m}$ and $27 \mu \mathrm{m})$ and sodium bicarbonate $(40 \mu \mathrm{m})$ did not improve the strength of the adhesive bond of resin composite to dentin. The strength of adhesion of the resin composite to dentin decreased significantly after air-abrasion of the tooth surface with erythritol-based powder.(International Journal of Biomedicine. 2021;11(4):451-455.)
\end{abstract}

Key Words: air abrasion $\bullet$ dentin $\bullet$ shear bond strength

For citation: Melkumyan TV, Musashaykhova ShK, Daurova FYu, Kamilov NKh, Sheraliyeva, SSh, Dadamova AD. Effect of Air-Abrasion on Shear Bond Strength of Resin Composite to Dentin: A Study in Vitro. International Journal of Biomedicine. 2021;11(4):451-455. doi:10.21103/Article11(4)_OA10

\section{Introduction}

The longevity of cosmetic dental restorations is mainly limited by the quality of the adhesive bonding of composite materials with dentin and enamel because under conditions in the oral cavity, adhesive and hybrid layers are exposed to progressive degradation..$^{(1-3)}$

*Corresponding author: Prof. Timur V. Melkumyan. Tashkent State Dental Institute, Tashkent, Uzbekistan. E-mail: t.dadamov@ gmail.com
For many years of practical experience and scientific research in the field of adhesive dentistry, it has been emphasized that a poor integration of resin material with tooth hard tissues is among the most frequently mentioned reasons for the loss of adhesive restorations and contributes to a violation of marginal seal and development of carious demineralization. ${ }^{(4-7)}$

Reliable adhesion of resin composite to dentin substrate may be determined by the formation of a hybrid layer resulting from the penetration of adhesive into the dentinal tubules, forming adhesive tags. Concurrently, there is a great deal of 
evidence indicating a noticeable improvement in the strength of adhesion of resin materials to dentin, especially in surface segments with a high density of dentinal tubules. Therefore, a perfect infiltration of an etched dentin surface with adhesive resin would yield a greater number of adhesive tags and better integration. ${ }^{(8-10)}$ However, in accordance with the results of other studies, there is no correlation between adhesive bond strength, depth of resin penetration, and the number of resin tags. ${ }^{(11,12)}$

Nevertheless, achieving a strong adhesion of resin composites to the tooth dentin is not easy because of relatively high moisture and organic content in the tissue. Also, there is a smear layer on a tooth surface, which occurs after the preparation of the carious cavity and negatively influences dentin bonding. ${ }^{(13,14)}$ Removal of the smear layer is a necessary step when a totaletch approach is chosen, and for many decades a phosphoric acid in the form of gels has been used to make it. ${ }^{(15,16)}$

However, due to the extension of indications for the application of air-abrasion in professional dental care, some studies have demonstrated the effectiveness of this method in adhesive dentistry in order to improve the surface microroughness and to increase the area of bonding surface. ${ }^{(17)}$ In addition, as a result of another study carried out in this field, it was found that the use of air-abrasion of the dentin surface after traditional preparation using conventional rotary instruments would contribute to a significant decrease in the thickness of the smear layer. ${ }^{(18)}$

It should be noted that for a long time the main instruments used for mechanical preparation of hard tooth tissues still remain diamond and carbide burs. However, because new devices and materials are used in adhesive dentistry for making air-abrasive preparations, there is an urgent need for preliminary in vitro studies in order to assess their influence on the quality and strength of adhesion to hard tooth tissues. ${ }^{(19,20)}$

In dentistry, alumina and sodium bicarbonate abrasive powders are among the most commonly used for tooth surface abrasion with air-born particles. However, taking into account the results of a large number of studies that indicate the probable loss of healthy hard tissue during pseudo-mechanical tooth preparation using compressed air and inorganic powders, low-abrasive organic particles, such as erythritol, began to find their place in daily practice. ${ }^{(21-23)}$

Available databases contain a large amount of inconsistent data indicating both the positive and negative efficiency of using air-abrasive powders based on alumina and sodium bicarbonate to improve the adhesion of composite materials to tooth hard tissues. ${ }^{(22,24,25)}$ These databases also lack information highlighting the consequences of the air-abrasion with low-abrasive particles. For these reasons, the purpose of this study was to evaluate in vitro the efficacy of alumina, sodium bicarbonate and erythritol-based tooth air-abrasion on shear bond strength (SBS) of resin composite to dentin.

\section{Material and Methods}

In order to assess the strength of the adhesive bond of the resin composite to tooth dentin, 50 tooth samples were prepared in accordance with the Ultradent Shear Bond Test method.
On all samples, in order to get a uniform smear layer, the surface of dentin was treated with an application of tungsten carbide bur under constant water cooling. The prepared surfaces were rinsed with a water spray for 30 seconds and dried using an air-water syringe of the dental unit. After that, all samples were divided into 5 groups. In Group $1(n=10)$ and Group $2(n=10)$, for air-abrasion of dentin surface 2 powders based on aluminum oxide with a particle size of $50 \mu \mathrm{m}$ and $27 \mu \mathrm{m}$, respectively, were used (RONDOflex plus 360, KaVo, Biberach, Germany). In Group $3(n=10)$ and Group 4 $(n=10)$, other abrasive powders based on sodium bicarbonate $(40 \mu \mathrm{m})$ and erythritol $(14 \mu \mathrm{m})$, respectively, were used for a similar purpose (Air-Flow Classic comfort, Air-Flow Plus, EMS, Nyon, Switzerland). The control group (Group 5, n=10) consisted of the remaining tooth samples in which the dentin surface, after preparation with a carbide bur, was not subjected to an air-abrasion.

In each case of air-abrasion, the nozzle of the instrument was angulated at $45^{\circ}$ to the dentin surface. The treatment was carried out with a constant stream of particles under $0.25 \mathrm{MPa}$ pressure in a handpiece for 30 seconds, slowly moving a nozzle with sweeping motions above the surface of tooth samples at a distance of $5 \mathrm{~mm}$, after which the tooth surface was thoroughly washed with an air-water spray for 30 seconds.

In all samples, the adhesive protocol was carried out by means of the wet bonding method using the adhesive resin OptiBond Solo Plus (Kerr, Italia).

Dentin etching was carried out for 15 seconds using a $37 \%$ phosphoric acid gel (FineEtch $\AA 37$, Spident Co., Ltd, Korea), after which the etched surface was rinsed with distilled water for 15 seconds and excess moisture was carefully blotted out. Application and polymerization of adhesive resin were done in accordance with the manufacturer's instructions. The light-curing composite GRADIA DIRECT (Japan) served as a resin composite of choice. The composite was cured for 20 seconds using a VALO lamp (Ultradent Products Inc., USA) in a standard mode.

The one-day adhesive strength of bonded interfaces was evaluated on an UltraTester device (Ultradent Products Inc., USA) after resin bonding without aging simulation. The speed of movement of the test clamp with the installed sample was set to $1 \mathrm{~mm} / \mathrm{min}$. The maximal value of bonding failure was fixed in pounds (lb).

The dentin surface ultrastructure was studied on 10 additional tooth samples, which were prepared for SEM analysis. The dentin surface was treated in accordance with the methods used in the study. Therefore, there were 2 tooth samples for each of the 5 methods of dentin surface treatment.

After an appropriate mechanical treatment of the dentin surface in each group all prepared samples were thoroughly washed for 30 seconds and dried using a water-air syringe. Before the SEM analysis, the dried samples were coated with a $10 \mathrm{~nm}$ thick layer of gold on a magnetron sputtering machine (Quorum Q150R ES, UK). Morphological studies of the dentin surface were carried out using a scanning electron microscope SEM - EVO MA 10 (Zeiss, Germany). Images were taken using SmartSEM software. 
Statistical analysis was performed using StatSoft Statistica v6.0. The mean (M) and standard deviation (SD) were calculated. Multiple comparisons were made with oneway ANOVA and post-hoc Tukey HSD test. A probability value of $P<0.05$ was considered statistically significant.

\section{Results}

Results obtained after evaluation of the SBS of resin composite adhesion to tooth dentin are presented in Table 1. According to the presented data, the lowest SBS among the groups was demonstrated in Group 4. The SBS values in Groups 1, 2,3, and the control group did not differ significantly. The SBS value in Group 3 was slightly higher than in Group 4. The SBS value in Group 4 was significantly lower than in the control group (Group 5) and Group 1.

Table 1.

SBS of resin composite adhesion to tooth dentin in the study groups

\begin{tabular}{|l|c|c|c|c|c|}
\hline Variable & Group 1 & Group 2 & Group 3 & Group 4 & Group 5 \\
\hline SBS, lb & $28.53 \pm 4.13$ & $27.61 \pm 3.44$ & $25.92 \pm 6.0$ & $23.05 \pm 3.33$ & $28.35 \pm 3.3$ \\
\hline \multirow{3}{*}{ Statistics } & \multicolumn{3}{|c|}{$\begin{array}{l}\mathrm{P}=0.0282 ; \mathrm{P}_{1-2}=0.9876, \mathrm{P}_{1-3}=0.6307 ; \mathrm{P}_{1-4}=0.0393, \\
\mathrm{P}_{1-5}=1.0000 \mathrm{P}_{2-3}=0.8929, \mathrm{P}_{2-4}=0.1218, \mathrm{P}_{2-5}=0.9946, \\
\mathrm{P}_{3-4}=0.5429, \mathrm{P}_{3-5}=0.6904, \mathrm{P}_{4-5}=0.0498\end{array}$} \\
\hline
\end{tabular}

During the analysis of micrographs taken from the surface of tooth samples of the control group, it was found that preparation of dentin using a rotary instrument had led to the formation of a pronounced smear layer with a small number of visible tubule orifices (Fig.1). However, the use of air-abrasive powders had facilitated an effective removal of the smear layer from the dentin surface of tooth samples, exposing a large number of dentinal tubules in all experimental groups (Fig.2-5).

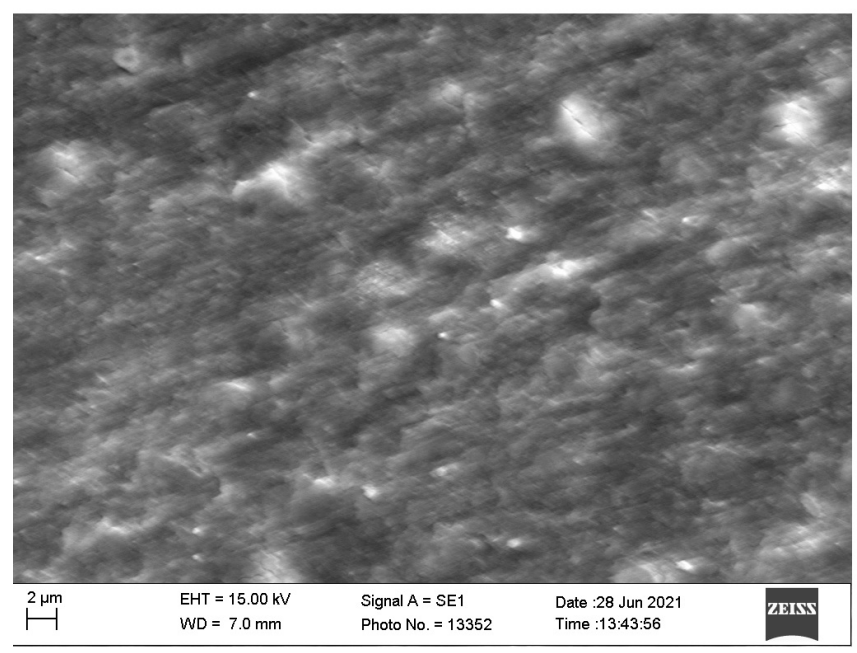

Fig. 1. Dentin surface after preparation with a tungsten carbide bur $(\times 2000)$

The comparative analysis of configurations of $2 \mathrm{D}$ profiles of different dentin surface segments in samples of Groups 1 and 2 (Fig.2,3) did not reveal significant visual differences. It was also found that on the dentin surface of samples in Groups 3 and 4, there were abrasive powder residues, especially in samples abraded with erythritol (Fig.4).

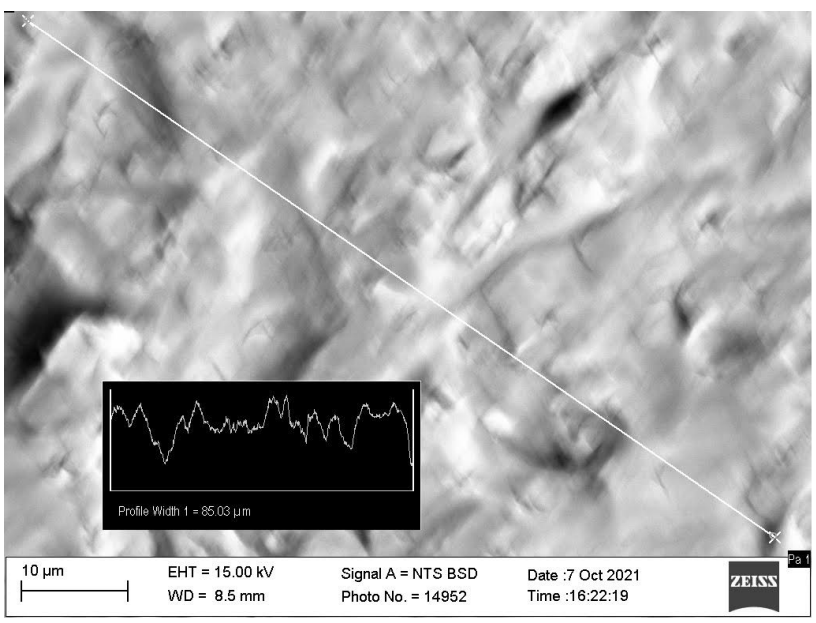

Fig. 2. Dentin surface after preparation with alumina powder with a particle size of $50 \mu \mathrm{m}(\times 1500)$

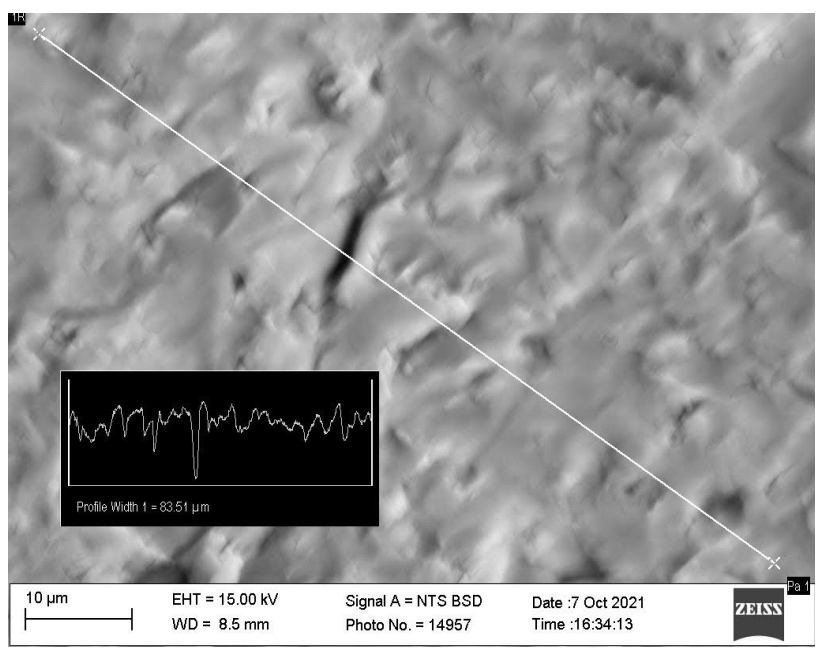

Fig. 3. Dentin surface after preparation with alumina powder with a particle size of $27 \mu \mathrm{m}(\times 1500)$

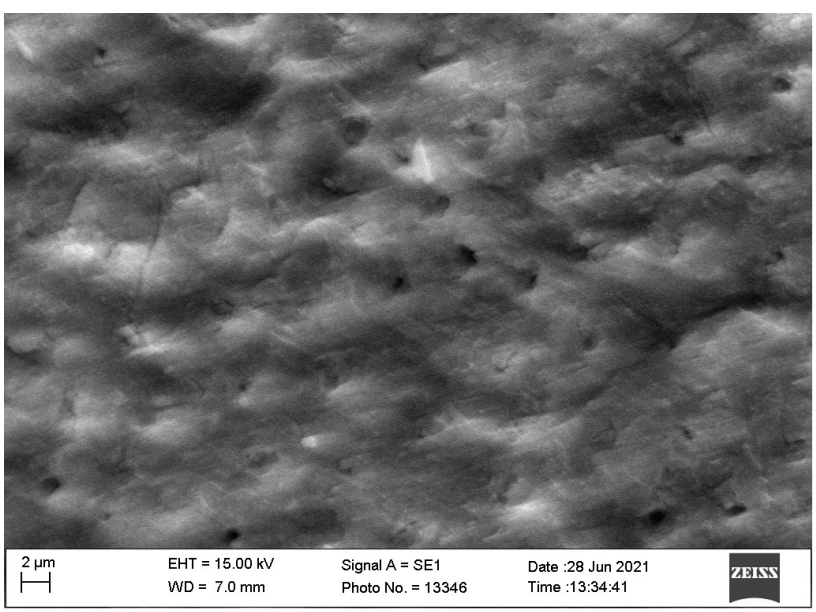

Fig. 4. Dentin surface after preparation with sodium bicarbonate $(40 \mu \mathrm{m})(\times 2000)$ 


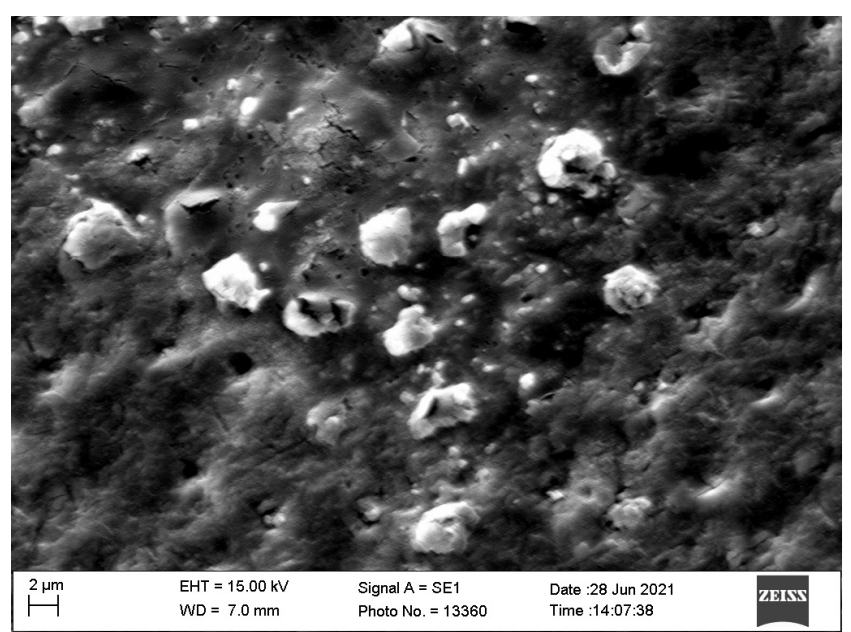

Fig. 5. Dentin surface after preparation with erythritol (14 $\mu \mathrm{m})$ $(\times 2000)$

\section{Discussion}

The possibility of effective use of air-abrasive powders for the preparation of dental tissues was proposed for the first time by R.B. Black. ${ }^{(26)}$ However, due to the high cost of the method and absence of high-velocity suction units, time consumption, and lack of technologies and materials at that time to perform highly aesthetic tooth restorations, this approach to tooth preparation was not as much demanded as the traditional method of cutting affected hard tissues with rotary instruments.

Revival of air-abrasion technology for tooth cleaning and preparation was not just facilitated by the understanding of the entire complexity of tooth enamel and dentin surface ultrastructure, but also by the emergence of nanomaterials for tooth cosmetic restoration and instructions for performing a proper adhesion in order to get long-term aesthetic and functional treatment results. ${ }^{(27)}$

In fact, an air-abrasion of natural pits and fissures facilitates detection of the extent of enamel demineralization in the presence of a diagnosed decay and also helps to perform high-quality cleaning of tooth surfaces from organic deposits and microbial biofilm. ${ }^{(28)}$

Nevertheless, despite the extensive knowledge in the field of tooth hard tissue air-abrasive preparation, the number of studies in the discipline does not decrease, which is directly related to the development and implementation of new abrasive powders.

The present study was aimed at investigating the effect of different air-abrasive treatment strategies on the adhesion strength of resin composite to dentin without aging. We used 3 traditional abrasive powders based on $\mathrm{Al} 2 \mathrm{O} 3(50 \mu \mathrm{m}$ and $27 \mu \mathrm{m})$ and sodium bicarbonate, and a relatively new powder based on erythritol, which is a food polyol. It is soluble in water and has a lower relative surface hardness, according to the Mohs scale.

Examination of micrographs of the dentin surface treated with an abrasive powder based on erythritol revealed particle residues in some areas, which was apparently a result of the destruction of larger particles upon collision with the dentin surface. Most of the residues were located in the orifices of dentinal tubules and might represent a mechanical obstacle for penetration of the adhesive resin into dentin.

A similar analysis of micrographs obtained from the dentin surface of samples of Groups 1,2, and 3 revealed that only in the case of sodium bicarbonate abrasion were there sporadic fragments of abrasive particles, which could be seen on the dentin surface. However, it did not result in a significant decrease in adhesive strength when compared with other groups.

In the present study, the adhesion strength of resin composite to tooth dentin in samples of the control group, in which traditional adhesive protocol was used according to the Etch \& Rinse principle, did not have a statistical difference from the mean value when compared with other groups where the main part of the smear layer was removed by air-abrasion before an etching step. The same results were confirmed by other researchers who used abrasives based on alumina $(50 \mu \mathrm{m})$ and different adhesive resins in an attempt to improve adhesion to dentin. They concluded that air-abrasion allows decreasing the thickness of the smear layer and increases the thickness of the hybrid layer. However, the bond strength was slightly improved due to the large number of defects observed in the hybrid layer on the dentin surface. ${ }^{(29-31)}$ Besides, air-abrasive treatment of tooth surfaces using alumina-based powders caused a loss of hard tissues. ${ }^{(22,32)}$

In the present study, during the preparation of several tooth samples, excessive dentin tissue removal was also noted with the formation of pits on the surface of samples after airabrasion with $50 \mu \mathrm{m}$ alumina particles.

Thus, within the limits of the study, it was found that the treatment of dentin surface with air-abrasive powders based on alumina ( $50 \mu \mathrm{m}$ and $27 \mu \mathrm{m})$ and sodium bicarbonate $(40 \mu \mathrm{m})$ did not improve the strength of the adhesive bond of resin composite to dentin. The strength of adhesion of the resin composite to dentin decreased significantly after air-abrasion of the tooth surface with erythritol-based powder.

\section{Conflict of Interests} interest.

The authors declare that they have no conflicts of

\section{References}

1. Frassetto A, Breschi L, Turco G, Marchesi G, Di Lenarda R, Tay FR, Pashley DH, Cadenaro M. Mechanisms of degradation of the hybrid layer in adhesive dentistry and therapeutic agents to improve bond durability--A literature review. Dent Mater. 2016 Feb;32(2):e41-53. doi: 10.1016/j. dental.2015.11.007.

2. Tjäderhane L. Dentin bonding: can we make it last? Oper Dent. 2015 Jan-Feb;40(1):4-18. doi: 10.2341/14-095-BL.

3. Matos AB, Trevelin LT, Silva BTFD, Francisconi-Dos-Rios LF, Siriani LK, Cardoso MV. Bonding efficiency and durability: current possibilities. Braz Oral Res. 2017 Aug 28;31(suppl 1):e57. doi: 10.1590/1807-3107BOR-2017.vol31.0057.

4. Braga RR, Ballester RY, Ferracane JL. Factors involved 
in the development of polymerization shrinkage stress in resin-composites: a systematic review. Dent Mater. 2005 Oct;21(10):962-70. doi: 10.1016/j.dental.2005.04.018.

5. Ishikiriama SK, Mondelli RF, Kano SC, Ishikiriama A, Mondelli J. Role of additional retention on marginal adaptation and sealing of large resin composite Class II restorations. Oper Dent. 2007 Nov-Dec;32(6):564-70. doi: 10.2341/06-158.

6. Turkistani A, Nakashima S, Shimada Y, Tagami J, Sadr A. Microgaps and Demineralization Progress around Composite Restorations. J Dent Res. 2015 Aug;94(8):1070-7. doi: 10.1177/0022034515589713.

7. Van Meerbeek B, Perdigão J, Lambrechts P, Vanherle G. The clinical performance of adhesives. J Dent. 1998 Jan;26(1):1-20. doi: 10.1016/s0300-5712(96)00070-x.

8. Anchieta RB, Oliveira FG, Sundfeld RH, Rahal V, Machado LS, Alexandre RS, Sundefeld ML, Rocha EP. Analysis of hybrid layer thickness, resin tag length and their correlation with microtensile bond strength using a total etch adhesive to intact dentin. Acta Odontol Latinoam. 2011;24(3):272-8.

9. Giachetti L, Bertini F, Scaminaci Russo D. Investigation into the nature of dentin resin tags: a scanning electron microscopic morphological analysis of demineralized bonded dentin. J Prosthet Dent. 2004 Sep;92(3):233-8. doi: 10.1016/j. prosdent.2004.06.021.

10. Schüpbach P, Krejci I, Lutz F. Dentin bonding: effect of tubule orientation on hybrid-layer formation. Eur J Oral Sci. 1997 Aug;105(4):344-52. doi: 10.1111/j.1600-0722.1997.tb00251.x.

11. Lohbauer U, Nikolaenko SA, Petschelt A, Frankenberger R. Resin tags do not contribute to dentin adhesion in selfetching adhesives. J Adhes Dent. 2008 Feb;10(2):97-103.

12. de Oliveira FG, Anchieta RB, Rahal V, de Alexandre RS, Machado LS, Sundefeld ML, Giannini M, Sundfeld RH. Correlation of the hybrid layer thickness and resin tags length with the bond strength of a self-etching adhesive system. Acta Odontol Latinoam. 2009;22(3):177-81.

13. van Landuyt K, De Munck J, Coutinho E, Peumans M, Lambrechts P, Van Meerbeek B. Bonding to Dentin: Smear Layer and the Process of Hybridization. In Eliades G, Watts DC, Eliades T, editors. Dental Hard Tissues and Bonding. Springer: Berlin/Heidelberg, Germany; 2005:89-122.

14. Miyazaki M, Tsubota $\mathrm{K}$, Takamizawa T, Kurokawa H, Rikuta A, Ando S. Factors affecting the in vitro performance of dentin-bonding systems. Jpn Dent Sci Rev. 2012;48(1):5360. doi:10.1016/j.jdsr.2011.11.002.

15. Paterson RC, Watts A. Dentine smear layer and bonding agents. Review: 1. Smear layer--nature of the smear layer. Restorative Dent. 1990 Aug;6(3):19-21.

16. Bowen RL, Eick JD, Henderson DA, Anderson DW. Smear layer: removal and bonding considerations. Oper Dent Suppl. 1984;3:30-4.

17. Lima VP, Soares K, Caldeira VS, Faria-E-Silva AL, Loomans B, Moraes RR. Airborne-particle Abrasion and Dentin Bonding: Systematic Review and Meta-analysis. Oper Dent. 2021 Jan 1;46(1):E21-E33. doi: 10.2341/19-216-L.
18. Bester SP, de Wet FA, Nel JC, Driessen CH. The effect of airborne particle abrasion on the dentin smear layer and dentin: an in vitro investigation. Int J Prosthodont. 1995 JanFeb;8(1):46-50.

19. de Oliveira MT, de Freitas PM, de Paula Eduardo C, Ambrosano GM, Giannini M. Influence of Diamond SonoAbrasion, Air-Abrasion and Er:YAG Laser Irradiation on Bonding of Different Adhesive Systems to Dentin. Eur J Dent. 2007 Jul;1(3):158-66.

20. Antunes LA, Pedro RL, Vieira AS, Maia LC. Effectiveness of high speed instrument and air abrasion on different dental substrates. Braz Oral Res. 2008 Jul-Sep;22(3):235-41. doi: 10.1590/s1806-83242008000300008.

21. Johnson King O, Milly H, Boyes V, Austin R, Festy F, Banerjee A. The effect of air-abrasion on the susceptibility of sound enamel to acid challenge. J Dent. 2016 Mar;46:36-41. doi: 10.1016/j.jdent.2016.01.009

22. Banerjee A, Watson TF. Air abrasion: its uses and abuses. Dent Update. 2002 Sep;29(7):340-6. doi: 10.12968/ denu.2002.29.7.340.

23. Kröger JC, Haribyan M, Nergiz I, Schmage P. Air polishing with erythritol powder - In vitro effects on dentin loss. J Indian Soc Periodontol. 2020 Sep-Oct;24(5):433-440. doi: $10.4103 /$ jisp.jisp_414_19.

24. Mujdeci A, Gokay $\overline{\mathrm{O}}$. The effect of airborne-particle abrasion on the shear bond strength of four restorative materials to enamel and dentin. J Prosthet Dent. 2004 Sep;92(3):245-9. doi: 10.1016/j.prosdent.2004.05.007.

25. Malmström HS, Chaves Y, Moss ME. Patient preference: conventional rotary handpieces or air abrasion for cavity preparation. Oper Dent. 2003 Nov-Dec;28(6):667-71.

26. Black RB. Technique for non-mechanical preparation of cavities and prophylaxis. J Am Dent Assoc. 1945;32:955- 965. 27. Berry EA 3rd, Eakle WS, Summitt JB. Air abrasion: an old technology reborn. Compend Contin Educ Dent. 1999 Aug;20(8):751-4, 756, 758-9 passim; quiz 764.

28. Hegde VS, Khatavkar RA. A new dimension to conservative dentistry: Air abrasion. J Conserv Dent. 2010 Jan;13(1):4-8. doi: 10.4103/0972-0707.62632.

29. Freeman R, Varanasi S, Meyers IA, Symons AL. Effect of air abrasion and thermocycling on resin adaptation and shear bond strength to dentin for an etch-and-rinse and self-etch resin adhesive. Dent Mater J. 2012;31(2):180-8. doi: 10.4012/ dmj.2011-146.

30. Leite FR, Capote TS, Zuanon AC. Application of the total etching technique or self-etching primers on primary teeth after air abrasion. Braz Oral Res. 2005 Jul-Sep;19(3):198-202. doi: 10.1590/s1806-83242005000300008.

31. Manhart J, Mehl A, Schroeter R, Obster B, Hickel R. Bond strength of composite to dentin treated by air abrasion. Oper Dent. 1999 Jul-Aug;24(4):223-32.

32. Santos-Pinto L, Peruchi C, Marker VA, Cordeiro R. Evaluation of cutting patterns produced with air-abrasion systems using different tip designs. Oper Dent. 2001 MayJun;26(3):308-12. 